\title{
Trends and patterns of patient attendance at an oral rehabilitative tertiary care hospital in India during the COVID-19 pandemic
}

\section{Dear Editor,}

On January $31^{\text {st }}, 2020$, the World Health Organization (WHO) announced that the COVID-19 outbreak constituted an international public health emergency[1]. To prevent an upsurge in the number of cases across India, the central government imposed a nationwide lockdown that was initially scheduled from March $25^{\text {th }}$ to April $14^{\text {th }}$, 2020, but which was eventually extended until May 31 ${ }^{\text {st }}, 2020$, with progressive changes in restrictions[2-4]. As the lockdown did not cover the national healthcare system, medical and dental hospitals remained functional, but all nonessential services were suspended. Meanwhile, the government gradually lifted the lockdown over several phases referred to as "unlock periods."

It is very challenging to practice dentistry during a pandemic. In this context, the aerosols that are generated during procedures place dental professionals at high risk[5]. Among these professionals, prosthodontists are particularly prone to transmission, both directly through interactions with patients and indirectly through the handling of dental casts and prosthetic appliances that have been processed in laboratories[6]. With the progression of COVID-19, this made it necessary to restrict prosthodontic services to emergency cases, meaning that all elective procedures were deferred. To clarify, there are many situations in which prosthodontic attention is urgently required, as specified by the American Dental Association (ADA) guidelines[7], which divide dental care into four categories according to severity, ranging from dental emergencies (most severe) to non-urgent dental care (least severe).

This descriptive cross-sectional study was conducted at the Department of Prosthodontics, Goa Dental College and Hospital to understand trends in patient attendance during the pandemic. We included patients who sought treatment during the following periods:

1) Lockdown (LD) period, lasting from March $25^{\text {th }}$ to May $31^{\text {st }}, 2020$

2) Unlock (UL) period, lasting from June $1^{\text {st }}$ to August $7^{\text {th }}, 2020$

3) Pre-COVID (PC) period, lasting from March $25^{\text {th }}$ to May $31^{\text {st }}, 2019$

Since the LD period lasted 69 days, the UL and PC periods were also restricted to the same duration to achieve uniformity. Data extraction was performed, descriptive statistics were computed, and a Chi-square test was conducted to assess the association between categorical variables using the Statistical Package for Social Sciences (SPPS) version 25. We found that the median of the number of patients who visited the department was 1, 4, and 13 patients per day during the LD, UL, and PC periods, respectively, with male-to-female ratios of 1.44:1, 1.54:1, and 0.69:1, respectively. This difference was statistically significant $(p=0.00)$. The proportions of patients visiting for "non-urgent" procedures were significantly higher during the PC and UL periods when compared to the LD period. During all periods, a significant number of patients who reported to the department for complaints related to removable prostheses were in the older age group ( $>55$ years), while most complaints related to fixed prostheses were submitted by younger patients (36-55 years). The youngest age

Table 1. Demographic characteristics of patients visiting the Department of Prosthodontics during Pre COVID-19, lockdown and unlock phase

\begin{tabular}{|c|c|c|c|c|}
\hline & $\begin{array}{c}\text { Pre COVID - } 19 \\
(808) \\
\text { N (\%) }\end{array}$ & $\begin{array}{l}\text { Lockdown (56) } \\
\text { N (\%) }\end{array}$ & $\begin{array}{l}\text { Unlock (232) } \\
\mathrm{N}(\%)\end{array}$ & $\mathrm{p}$ value \\
\hline \multicolumn{5}{|l|}{ Gender } \\
\hline Male & $330(40.8)$ & $33(58.9)$ & $141(60.8)$ & $0.00^{*}$ \\
\hline Female & $478(59.2)$ & $23(41.1)$ & $91(39.2)$ & \\
\hline \multicolumn{5}{|l|}{ Age } \\
\hline$<1$ year & $9(1.1)$ & $1(1.8)$ & $13(5.6)$ & $0.001^{*}$ \\
\hline $18-35$ years & $115(14.2)$ & $12(21.4)$ & $50(21.6)$ & \\
\hline $36-55$ years & $315(39)$ & $21(37.5)$ & $78(33.6)$ & \\
\hline$>55$ years & $369(45.7)$ & $22(39.3)$ & $91(39.2)$ & \\
\hline \multicolumn{5}{|l|}{ Location } \\
\hline Urban & $324(40.1)$ & $44(78.6)$ & $157(67.7)$ & $0.00^{*}$ \\
\hline Rural & $484(59.9)$ & $12(21.4)$ & $75(32.3)$ & \\
\hline \multicolumn{5}{|l|}{ Complaint } \\
\hline Removable Prosthodontics (Broken + adjustment) & $107(13.2)$ & $17(30.4)$ & $62(26.7)$ & $0.00^{*}$ \\
\hline Fixed Prosthodontics (Dislodged + Failed) & $84(10.4)$ & $22(39.3)$ & $73(31.5)$ & \\
\hline $\begin{array}{l}\text { Referred cases (Cranial alloplastic implants+ TMDs and other } \\
\text { maxillo-facial prostheses) }\end{array}$ & $36(4.4)$ & $3(5.4)$ & $15(6.5)$ & \\
\hline Implant Prosthodontics (Broken + adjustment) & $12(1.5)$ & $1(1.8)$ & $13(5.6)$ & \\
\hline Naso Alveolar Moulding & $9(1.1)$ & $1(1.7)$ & $14(6)$ & \\
\hline Non urgent prosthodontic procedures & $559(69.2)$ & $12(21.4)$ & $55(23.7)$ & \\
\hline
\end{tabular}


Table 2. Complaints of patients visiting the Department of Prosthodontics during Pre-COVID-19, Lockdown and Unlock phase

\begin{tabular}{|c|c|c|c|c|c|c|}
\hline & \multicolumn{2}{|c|}{$\begin{array}{c}\text { Pre COVID-19 } \\
\text { N (\%) }\end{array}$} & \multicolumn{2}{|c|}{$\begin{array}{l}\text { Lockdown } \\
\text { N (\%) }\end{array}$} & \multicolumn{2}{|c|}{$\begin{array}{l}\text { Unlock } \\
\mathrm{N}(\%)\end{array}$} \\
\hline & $\begin{array}{l}\text { Male } \\
\text { N (\%) }\end{array}$ & $\begin{array}{l}\text { Female } \\
\mathrm{N}(\%)\end{array}$ & $\begin{array}{l}\text { Male } \\
\mathrm{N}(\%)\end{array}$ & $\begin{array}{c}\text { Female } \\
\mathrm{N}(\%)\end{array}$ & $\begin{array}{l}\text { Male } \\
\mathrm{N}(\%)\end{array}$ & $\begin{array}{c}\text { Female } \\
\mathrm{N}(\%)\end{array}$ \\
\hline Broken Denture & 18 & 39 & 10 & 2 & 23 & 23 \\
\hline $18-35$ years & $2(11.1)$ & $6(15.4)$ & & & & \\
\hline $36-55$ years & $4(22.2)$ & $17(43.6)$ & & & $4(17.2)$ & $4(17.2)$ \\
\hline$>55$ years & $12(66.7)$ & $16(41)$ & $10(100)$ & $2(100)$ & 19 (82.6) & $19(82.6)$ \\
\hline Denture adjustment & 22 & 28 & 2 & 3 & 18 & 18 \\
\hline $18-35$ years & $2(9.1)$ & $1(3.6)$ & & & $1(5.6)$ & $1(5.6)$ \\
\hline $36-55$ years & $2(9.1)$ & $13(46.4)$ & & $2(66.7)$ & $5(27.8)$ & $5(27.8)$ \\
\hline$>55$ years & $18(81.8)$ & $14(50)$ & $2(100)$ & $1(33.3)$ & $12(66.7)$ & $12(66.7)$ \\
\hline Dislodged restoration & 18 & 22 & 7 & 8 & 38 & 38 \\
\hline $18-35$ years & $4(22.2)$ & $5(22.7)$ & $2(28.6)$ & $1(12.5)$ & $16(42.1)$ & $16(42.1)$ \\
\hline $36-55$ years & $7(38.9)$ & $13(59.1)$ & $4(57.1)$ & $6(75)$ & $16(42.1)$ & $16(42.1)$ \\
\hline$>55$ years & $7(38.9)$ & $4(18.2)$ & $1(14.3)$ & $1(12.5)$ & $6(15.8)$ & $6(15.8)$ \\
\hline Failed restoration & 15 & 29 & 4 & 3 & 11 & 11 \\
\hline $18-35$ years & $1(6.7)$ & $6(20.7)$ & $2(50)$ & $1(33.3)$ & $5(45.5)$ & $5(45.5)$ \\
\hline $36-55$ years & $10(66.7)$ & $19(65.5)$ & $2(50)$ & $1(33.3)$ & $4(25)$ & $4(25)$ \\
\hline$>55$ years & $4(26.7)$ & $4(13.8)$ & & $1(33.3)$ & $2(18.2)$ & $2(18.2)$ \\
\hline Cranial alloplastic implants & 19 & 5 & 1 & & 5 & 5 \\
\hline $18-35$ years & $13(68.4)$ & $1(20)$ & - & & $3(60)$ & $3(60)$ \\
\hline $36-55$ years & $6(31.6)$ & $2(40)$ & $1(100)$ & & $2(40)$ & $2(40)$ \\
\hline$>55$ years & & $2(40)$ & & & & \\
\hline TMDs & 5 & 6 & 2 & & 2 & 2 \\
\hline $18-35$ years & $2(3.3)$ & $2(33.3)$ & $1(50)$ & & & \\
\hline $36-55$ years & $2(33.3)$ & $3(50)$ & $1(50)$ & & $1(50)$ & $1(50)$ \\
\hline$>55$ years & $1(100)$ & $1(16.7)$ & & & $1(50)$ & $1(50)$ \\
\hline Other Maxillofacial Prostheses & & & & & 5 & 5 \\
\hline $18-35$ years & & & & & $1(20)$ & $1(20)$ \\
\hline $36-55$ years & & & & & $1(20)$ & $1(20)$ \\
\hline$>55$ years & & & & & $3(60)$ & $3(60)$ \\
\hline Implant prostheses & 3 & 9 & & 1 & 8 & 8 \\
\hline $18-35$ years & $1(33.3)$ & $4(44.4)$ & & $1(100)$ & $1(12.5)$ & $1(12.5)$ \\
\hline $36-55$ years & $2(66.7)$ & $5(55.6)$ & & & $5(62.5)$ & $5(62.5)$ \\
\hline$>55$ years & & & & & $2(25)$ & $2(25)$ \\
\hline Non urgent prosthodontic procedures & 224 & 335 & 7 & 5 & 31 & 31 \\
\hline $18-35$ years & $27(12.1)$ & $38(11.3)$ & $3(42.9)$ & $1(20)$ & $6(19.4)$ & $6(19.4)$ \\
\hline $36-55$ years & $75(33.5)$ & $135(40.3)$ & $2(28.6)$ & $2(40)$ & $8(25.8)$ & $8(25.8)$ \\
\hline$>55$ years & $122(54.5)$ & $162(48.4)$ & $2(28.6)$ & $2(40)$ & $17(54.8)$ & $17(54.8)$ \\
\hline
\end{tabular}

group (18-35 years) accounted for the highest number of cases reported for the fabrication of cranial alloplastic implants. In addition, a significantly higher proportion of patients from urban areas visited the department during the LD period when compared to the UL and PC periods $(p=0.00)$. Tables 1 and 2 respectively list the relevant demographic distributions and the complaints of cases reported to the department.

The reasons for the reduced numbers during the LD period were obvious, including the fear of disease infection, public transport suspensions, and government instructions to avoid venturing outdoors unless it was absolutely essential. Indeed, the present findings are consistent with those previously reported in similar studies[8,9]. Despite the above concerns, some patients still presented with com- plaints. Of particular note, the majority of these patients were from the urban population, who may have had access to private vehicles, which made it easier to report to the department. It is thus plausible that the primary feature among patients who reported to the department during the LD period was the combination of a self-perceived emergency and access to a mode of transport. On the other hand, patients from rural areas had higher visitation rates during the UL and PC periods. As there would have also been cases of self-perceived emergency in these areas, this finding highlights the fact that patients could not report to the department due to the lack of transport, or simply refrained because they prioritized COVID-19 concerns over prosthodontic urgency. It is possible that these patients first reported to primary health centers, which cater to basic oral care needs in rural and urban areas, but were then referred to the tertiary care 
center because the level of required care was outside the primary health center scope. Due to the requirements for enhanced disinfection and sterilization measures in addition to the administration of specialized treatments, most, if not all, of the above cases would have been referred to the tertiary care center after initial screening.

The results also revealed that more female patients visited the department during the PC period, while more male patients visited during the LD and UL periods. A possible explanation for this could be the disengagement from work due to the government's suspension of all non-essential services. Individuals who were free from work-related preoccupations would have found it easier to report to the department despite the fear of COVID-19.

During the PC period, the majority of patients reported to the department to receive adjustments to removable prostheses. By contrast, most patients reported to receive treatment for existing fixed prosthesis during the LD and UL periods. This finding can be attributed to the fact that most patients with complaints preferred not to wear their removable prosthesis rather than venture out during the pandemic. Conversely, patients with existing fixed prostheses had to visit the department for service, even during the LD and UL periods. The most common fixed prosthodontic treatment was the removal of an existing fixed prosthesis to facilitate emergency endodontic treatment or the extraction of abutment teeth.

The LD period significantly impacted the admission of patients who followed time-bound treatment schedules, including those pertaining to cranial prostheses, pre-surgical naso-alveolar molding (PNAM), and other maxillofacial rehabilitations. These patients reported to the department soon after the LD period; as a result, we observed a spike in these cases during the UL period. There was also an upsurge in dental implant-related emergencies during the UL period when compared to the LD period. Only $6.9 \%$ and $28.71 \%$ of the usual PC period numbers were reported during the LD and UL periods, respectively.

This study produced an actual quantification of patient footfalls in the prosthodontics department, which may help frame guidelines for future incidents. By examining the COVID-19 pandemic and its effects, we can better estimate and specifically cater to population needs. This precise quantification should facilitate the establishment of guidelines for appropriate resource and personnel allocation in the future. Meanwhile, the evaluation of the number of reporting patients should help determine the need for specific materials, infrastructures, precise staff numbers, and critical skills to prepare institutional facilities for similar events in the future.

\section{Conflicts of interest}

The authors declare that there are no conflicts of interest.

\section{References}

[1] Mahase E. China coronavirus: WHO declares international emergency as death toll exceeds 200. BMJ. 2020;368:m408. https://doi.org/10.1136/bmj. m408, PMID:32005727

[2] Government of India, Ministry of Home Affairs order No. 40-3/2020-DM-I (A), MHA Guidelines for effective control of COVID-19, https://www.mha.gov.in/ sites/default/files/MHAOrder_23032021.pdf [accessed 23 March 2021]

[3] Government of India, Ministry of Home Affairs order No. 40-3/2020-DM-I (A), Government of India, Ministry of Home Affairs order No. 40-3/2020DM-I (A), New Guidelines on the measures to be taken by Ministries/ Departments of Government of India, State/UT Governments and State/UT authorities for containment of COVID-19 in the country for the extended period of national lockdown for a further period of two weeks with effect from $4^{\text {th }}$ may, 2020. https://www.mha.gov.in/sites/default/files/MHA\%20 Order\%20Dt.\%201.5.2020\%20to\%20extend\%20Lockdown\%20period\%20for\%202\%20weeks\%20w.e.f. $\% 204.5 .2020 \% 20$ with $\% 20$ new $\% 20$ guidelines.pdf [accessed 1 May 2020]

[4] Government of India, Ministry of Home Affairs order No. 40-3/2020-DM-I (A), Consolidated Revised Guidelines on the measures to be taken by Ministries/ Departments of Government of India, State/UT Governments and State/UT authorities for containment of COVID-19 in the country, https://dst.gov.in/ sites/default/files/MHA\%20order\%20dt\%2015.04.2020\%2C\%20with\%20 Revised\%20Consolidated\%20Guidelines.pdf [accessed 15 April 2020]

[5] Yonenaga K, Itai S, Hoshi K. Implications for clinical dental practice during the coronavirus disease pandemic: A scoping review. J Prosthodont Res. 2021;JPR_D_21_00064; Epub ahead of print. https://doi.org/10.2186/jpr. JPR_D_21_00064, PMID:34707074

[6] Batista AUD, Silva PLP, Melo LA, Carreiro AFP. Prosthodontic practice during the COVID-19 pandemic: prevention and implications. Braz Oral Res. 2021;35:e049. https://doi.org/10.1590/1807-3107bor-2021.vol35.0049, PMID:33729299

[7] What constitutes a dental emergency? ADA News; 2020 https://www.ada. org/en/publications/ada-news/2020-archive/march/ada-develops-guidance-on-dental-emergency-nonemergency-care [Accessed 8 April, 2020]

[8] Guo H, Zhou Y, Liu X, Tan J. The impact of the COVID-19 epidemic on the utilization of emergency dental services. J Dent Sci. 2020;15:564-7. https:// doi.org/10.1016/j.jds.2020.02.002, PMID:32296495

[9] Kranz AM, Chen A, Gahlon G, Stein BD. 2020 trends in dental office visits during the COVID-19 pandemic. J Am Dent Assoc. 2021;152:535-541.e1. https://doi.org/10.1016/j.adaj.2021.02.016, PMID:34023093

Aradhana Nagarsekara
Ridhima Birmani Gaunkar ${ }^{\text {b* }}$
Ashwin Mysorea
Kennedy Mascarenhas ${ }^{a}$
Meena Ajay Aras $^{a}$
aDepartment of Prosthodontics and Crown \& Bridge, Goa Dental College \&
Hospital, Bambolim, Goa, India
bDepartment of Public Health Dentistry, Goa Dental College and Hospital,
Bambolim, Goa, India
${ }^{*}$ Corresponding author
E-mail address: drbirmani@gmail.com

Received 3 September 2021, Accepted 31 October 2021, Available online 9 December 2021 DOI: https://doi.org/10.2186/jpr.JPR_D_21_00242

Copyright: $\odot 2021$ Japan Prosthodontic Society. All rights reserved. 